\title{
Evaluation of Molecularly Imprinted Polymer Pearls for Selective Isolation of Hypericins
}

\author{
ANA MIHAELA FLOREA ${ }^{1 \#}$, TANTA VERONA IORDACHE ${ }^{1 \#}$, ANAMARIA ZAHARIA ${ }^{1}$, BIANCA GEORGESCU1, \\ ANDREEA ELENA VOICU ${ }^{2}$, BOIKO TSYNTSARSKI ${ }^{3}$, GHEORGHE HUBCA ${ }^{4}$, ANDREI SARBU ${ }^{1 * \#}$ \\ ${ }^{1}$ National Research and Development Institute for Chemistry and Petrochemistry ICECHIM, Advanced Polymer Materials and \\ Polymer Recycling, 202 Splaiul Independentei, 060021 Bucharest, Romania. \\ 2Military Technical Academy, 39-49 George Cosbuc Blvd., 050141, Bucharest, Romania \\ ${ }^{3}$ Institute of Organic Chemistry, Bulgarian Academy of Sciences, Sofia 1113, Bulgaria \\ ${ }^{4}$ University Politehnica of Bucharest, The Faculty of Applied Chemistry and Material Science, Bioresources and Polymer Science \\ Department, 1-7 Polizu, 011061 Bucharest, Romania
}

This article describes the evaluation of molecularly imprinted polymers (MIPs) obtained by wet phase
inversion for facile separation of hypericins from Hypericum perforatum L. (or Saint John's Wort, SJ W). In
this respect, concentrated extracts containing hypericin and pseudohypericin were used as "phyto-
templates" for creating selective cavities into the pearl shaped MIPS. The obtained MIPS were characterized
by infrared and by thermal analyses. Chromatographic evaluation of the MIPS was performed relative to
blank samples and it was concluded that the pearls can retain selectively the hypericins from SJ W extracts.

Keywords: molecularly imprinted polymer, wet phase inversion, pearls, hypericin, pseudohypericin

One of the most versatile and viable techniques for tailormade polymers with specific molecular-recognition properties is considered to be molecular imprinting (MI). Since its discovery by Polyakov [1] and Wulff [2] in the 1930s and 1970s, MI is able to design synthetic sorbents with enhanced selectivity towards template structures [3], namely molecularly imprinted polymers (MIPs). MI usually includes a crosslinking polymerization process in the presence of a template molecule that is extracted afterwards, which leaves specific cavities in the imprinted matrix via commonly non-covalent or covalent interactions. What is more, the molecular information becomes complementary to the template in both topography and chemical functionality $[4,5]$. With regard to the nature of imprinting, the methods have been classified as chemical $\mathrm{Ml}$ and physical-chemical MI. The chemical methods imply imprinting during polymerization of monomer-template complexes generated in the self-assembly or the preorganization step. Physical-chemical imprinting a.k.a. phase inversion refers to creating specific cavities, selective for target molecules, in a post-polymerisation step. In the latter, a precursor solution of a linear polymer is mixed with template molecules to generate specific interactions; subsequently, the solution is precipitated in a proper non-solvent to create robust pearls or membranes [6-8]. Since MIPs are robust materials exhibiting low production cost, long-term stability and excellent recognition properties, the interest in employing these materials in many applications, including isolation, biosensors, catalysis, solid-phase extraction, membranes, drug delivery systems and energetic materials has rapidly increased [9-15]. Hypericum perforatum L. is the most studied of Hypericum genus and it is known for its antidepressant and anti-inflammatory activities, antioxidant and antimicrobial properties [16-18]. One of the major groups of natural photo-sensitizers of the SJW extracts belongs to naphtodianthrones (NTS). The NTs of interest are hypericins, i.e. hypericin $(H)$ and its structural analog pseudohypericin (PH), respectively. Several papers were published describing the isolation and purification of $\mathrm{H}$ and $\mathrm{PH}$ from $\mathrm{SJ}$ W, which mainly consist of solid-phase extraction [19], Soxhlet extraction, size exclusion column chromatography, high-speed counter-current chromatography or wet phase inversion method $[8,20]$. Nevertheless, MIPs with high adsorption capacity and selectivity are more adequate to separate such lowavailable principles. In a previous paper, we have pioneered the synthesis of MIP pearls with a phyto-extract as template for imprinting (using a purified $0.02 \mathrm{wt} \%$ NTs extract) for the subsequent retention of hypericin molecules from diluted naphtodianthrone extracts [20]. Herein, the imprinting with the phyto-template was also considered, but using a more concentrated extract of $0.03 \mathrm{wt}$. $\%$ NTs, to establish the effect of concentration upon MIPs selectivity. This method for preparing the MIPs pearls has great potential for application as a fast isolation method of hypericins from SJ W herbs.

\section{Experimental part}

\section{Materials and methods}

The reagents acrylonitrile (AN, $98 \%$ ) from ACROS Organics and methacrylic acid (MAA, 99\%) from Fluka were used for the obtaining of PAN-co-PMAA copolymer systems. The monomers were distilled before use, for inhibitor removal. Dimethylsulfoxide (DMSO, p.a. grade) from Scharlau and ethanol (EtOH, 99.6\%) from Chimopar were used as solvents. All other chemicals were analytical reagent grade. The hydro-alcoholic extract (30/70, v/v) from the superior part of SJ W flower (from Plantavorel Romania) was used as received. Distilled water used throughout the experiments was obtained from a laboratory purification system.

The imprinted (noted hereafter MIP $x-y$ ) and their homologues non-imprinted polymers (noted hereafter NIP $x$-y) were successfully prepared by following our previously reported work [20]. Briefly, the method consists of three relevant stages: copolymer synthesis (noted hereafter CS $x$, where $x$ represents the composition of copolymer); 
preparation of precursor copolymer solutions (noted as CS $x-y$ ) and obtaining of polymer pearls (MIP x-y and NIP x-y) (table 1). Firstly, the four CSx copolymers were synthesized by emulsion copolymerization without emulsifier. To prepare the precursor matrices, various weight ratios of AN: MAA were used (table 1). After the complete dissolution of CS $x$ powders ( 8 wt. \% relative to DMSO) in $100 \mathrm{~mL}$ DMSO (continuous stirring, room temperature) in light-protected flasks, imprinted solutions with $5 \mathrm{wt} \%$ or $10 \mathrm{wt} \%$ hydro-alcoholic extract were obtained. As a reference, the non-imprinted solutions were also prepared by the same protocol with a simple EtOH/W solvent mixture $[70 / 30, v / v]$ instead of the extract. Finally, the CS $x$ solutions were introduced into a syringe-like cartridge of the semi-automated dripping system and then converted into polymer pearls when contacted the water coagulation bath. The obtained pearls were washed several times with distilled water for DMSO removal; subsequently, in order to remove the phyto-template, they were washed thoroughly with ethanol for $4 \mathrm{~h}$ under continuous stirring and then dried for further characterization. It is newsw orthy to mention that the adsorption tests were carried out on wet pearls.

\section{Apparatus}

Rheological experiments were carried out with a model Rheostest 2.1 (Germany) viscometer having coaxial cylinders at $25^{\circ} \mathrm{C}$. For structural analyses, the pearls were dried at $60^{\circ} \mathrm{C}$ until constant weight (around $24 \mathrm{~h}$ ). FTIR spectra were recorded on a Fourier transform infrared spectrometer Bruker Tensor 37 Spectrometer (ATR device) in the $400-4000 \mathrm{~cm}^{-1}$ range using 16 scans with a $4 \mathrm{~cm}^{-1}$ resolution. Thermogravimetric analysis (TGA/DTG) were registered using Q500 TA Instrument. Each sample was heated from room temperature to $800^{\circ} \mathrm{C}$ at a rate of $10^{\circ} \mathrm{C}$ / min under a constant nitrogen flow rate. All binding and selectivity experiments were performed using a HPLC (Varian Prostar, Prostar 350 autosampler) equipped with a Mediterranea SEA C18, $5 \mu \mathrm{m} 15 \times 0.46 \mathrm{~cm}$ column (Teknokroma) and a diode array detector (DAD) at 593 nm. UV-Vis Spectrometer Thermo Nicolet Evolution 500 in the 400-800 nm wavelength range was used for detecting the concentration of NTs and to quantify the selectivity of pearls.

\section{Batch re-binding and selectivity experiments}

To clarify further the molecular recognition properties of the MIPs, the experiments were conducted relative to the blank, non-imprinted polymers (NIPs), fabricated under the same preparation conditions with the imprinted polymer but in the absence of template.

For a regular measurement, $600 \mathrm{mg}$ of wet pearls were mixed with $3 \mathrm{~mL}$ of extract properly diluted in the $10^{-4}-10^{-5}$ mole/L range (containing either $\mathrm{H}$ or $\mathrm{PH}$ ), at $25^{\circ} \mathrm{C}$ for $20 \mathrm{~h}$. The imprinting effect of pearls for $\mathrm{H}$ and $\mathrm{PH}$ against each other was determined by HPLC and the selectivity of pearls was analyzed by UV-Vis.

The binding capacity $Q$ (g compound/g pearls) of imprinted polymer pearls (MIPS) and their corresponding non-imprinted pearls (NIPs) was calculated using equation (1). The imprinting factor, IF quantified the specificity with which the MIP adsorbed $\mathrm{H}$ or PH relative to the NIP, and was determined as the ratio between the binding concentration of the MIP and that of the NIP (equation (2)).

$$
\begin{aligned}
& Q=\left(c_{i}-c_{f}\right) \cdot V_{S} / m_{p} \\
& I F=Q_{M I P} / Q_{N I P}
\end{aligned}
$$

\begin{tabular}{|c|c|c|}
\hline CS $\mathbf{x}$ & AN:MAA wt. \% ratio & ${\text { MIP } \mathbf{x}-\mathbf{y}^{*} / \mathbf{N I P} \mathbf{x}-\mathbf{y}^{*}}^{*}$ \\
\hline CS 1 & $90: 10$ & MIP 1-y/NIP 1-y \\
\hline CS 2 & $85: 15$ & MIP 2-y/NIP 2-y \\
\hline CS 3 & $80: 20$ & MIP 3-y/NIP 3-y \\
\hline CS 4 & $75: 25$ & MIP 4-y/NIP 4-y \\
\hline
\end{tabular}

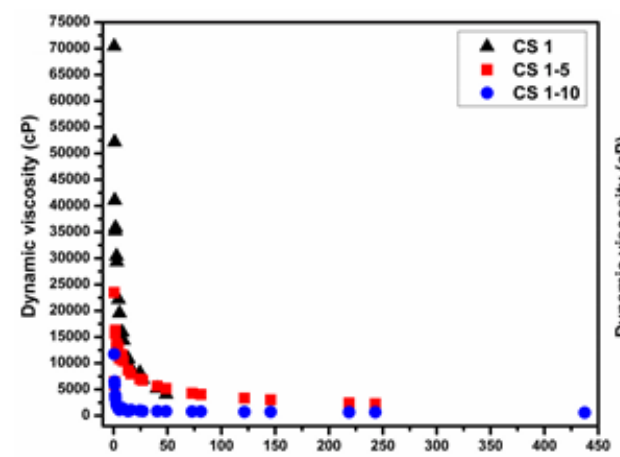

a

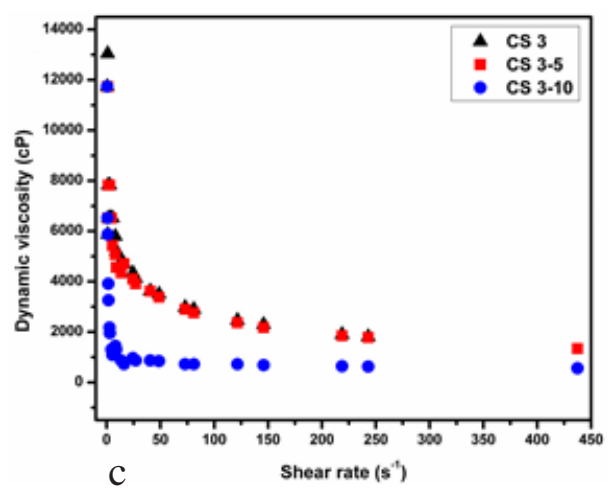

496

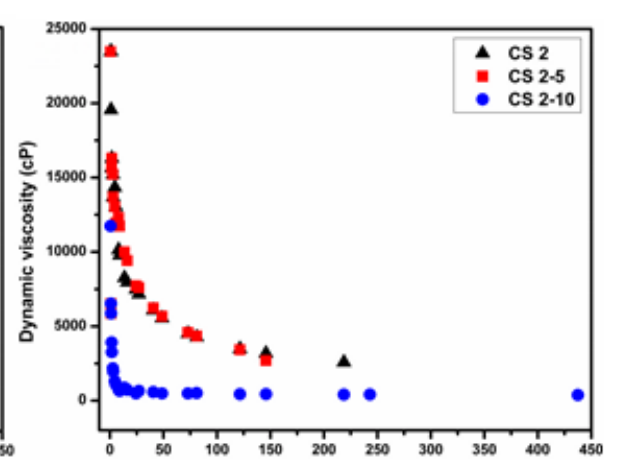

b

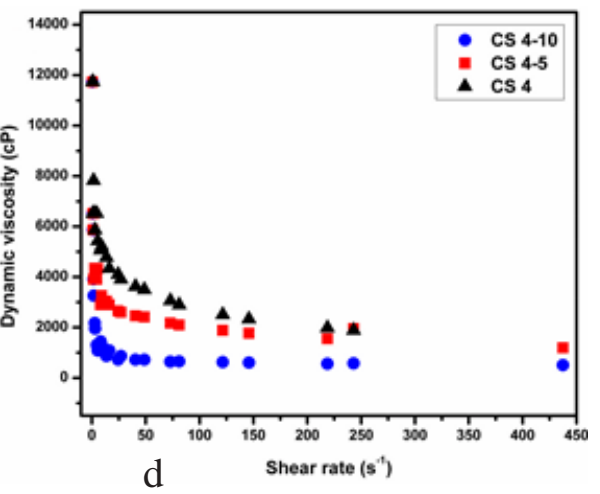

Table 1

NOTATIONS OF COPOLYMERS CS x AND OF NIPS AND MIPSPEARLS
Fig.1. Rheological behavior of: a) CS 1, b) CS 2, c) CS 3 and d) CS 4 imprinted solutions with $5 \%$ or $10 \%$ extract compared with non-imprinted solutions 
where $c_{f}(g / L)$ and $c_{f}(g / L)$ represents the initial and final concentrations of either $\mathrm{H}, \mathrm{PH}$, in the feed solution, $m_{\mathrm{r}}(\mathrm{g})$ is the amount of dry pearls taken into account and $V_{s}(\mathrm{R})$ is the volume of the feed solution.

The distribution coefficient $K_{d c_{n}}(\mathrm{~mL} / \mathrm{g})$ represented the amount of compound $C n$ bounded by $1 \mathrm{~g}$ of pearls relative to the amount of the same compound remaining in $1 \mathrm{~mL}$ of feed extract (equation (3)). Selectivity coefficient, $k$, (equation (4)) quantifies the binding affinity of MIPs for $\mathrm{H}$ or PH over their competitors (PH and $\mathrm{H}$, respectively); where the notation C1-C2 represented the H-PH or PH-H. A relative selectivity coefficient of $k^{\prime}$ was also defined in equation (5), which expresses the selectivity of MIPs in competitive adsorption relative to blank pearls-NIPs. The binding experiment was carried out in duplicate and the reproducibility was found to be $\pm 3 \%$.

$$
\begin{aligned}
& K_{d}=\left(c_{i}-c_{f}\right) \cdot V_{S} / c_{i} \cdot m_{p} \\
& k_{\mathrm{Cl}-\mathrm{C} 2}=K_{d, C 1} / K_{d, C 2} \\
& k_{\mathrm{Cl}}{ }^{\prime}=k_{\mathrm{C} 1-C 2, M I P} / k_{\mathrm{C1}-\mathrm{C} 2, \mathrm{NIP}}
\end{aligned}
$$

\section{Results and discussions}

Preparation and evaluation of molecularly imprinted polymers

Four MIP pearl types were synthesized by the wet phase inversion technique, in a similar way to Florea et al. [20], but using a more concentrated extract of $0.03 \mathrm{wt} . \%$ NTs as phyto-template, in order to obtain quantitative isolation of hypericins from SJW.

\section{Rheological behavior of CS $x$ solutions}

MAA monomer has been demonstrated to generate strong interactions with the hypericin molecules leading to stable complexes $[8,20]$. The formation of several hydrogen bonds considering the proximity of acidic and basic functional groups of the template is expected to influence the rheological behavior of copolymer solutions. To obtain appropriate flowing properties of the CS $x$ solutions for pearls extrusion, the content of the extract was optimized (herein $5 \mathrm{wt} . \%$ or $10 \mathrm{wt} . \%$ ). The rheological profiles (fig. 1. a)-d) of CS x imprinted solutions and their corresponding non-imprinted ones at 25을 indicate the influence of the dynamic viscosity upon the shear gradient. It can be seen that the rheological behavior is characterized bya pseudo-plastic flow for CS $x$ and CS $x-5$ (at low contents of extract) which afterwards turned into Newtonian flow at maximum contents of extract (CS x-10). Hence, the addition of $5 \%$ extract generates a similar rheological behavior to that of the control copolymer solution. The pseudo-plastic behavior of $5 \%$ imprinted solutions can be observed at relatively low shear gradient values (50 - 100 $\mathrm{s}^{-1}$ ) and can be attributed to the formation of intramolecular and intermolecular hydrogen bonds due to acrylonitrile component. Futhermore, with the increase in the extract content from 5 to $10 \%$, the phyto-template has an obvious influence on the initial Newtonian behavior of CS $x$ solutions in DMSO due to the fact that the extract is also a Newtonian fluid. Therefore, above $150 \mathrm{~s}^{-1}$ shear rates the viscosity of imprinted solutions is almost constant on a wide range of shear gradients. CS 4-5 solution (fig. 1. d)) presented the most appropriate rheological behavior, closest to Newtonian. These results indicated that the extract has a quite interesting influence upon the general rheological character of copolymer solutions.

\section{Structure characterization of MIPS}

FTIR analysis was carried out to analyze the structural details of NIPS and MIPs before and after template removal. In the FTIR spectra of NIP x-10 and MIP x-10 (fig. 2.), it can be seen that the samples present similar characteristic bands for copolymers. To highlight the imprinting effect of the phyto-template, spectroscopic analyses were performed for $\mathrm{H}$ and $\mathrm{PH}$ (table 2), as well. Hence, they all show specific bands in the $2935-2939 \mathrm{~cm}^{-1}$ range which can be assigned to $\mu_{C H}$ stretching vibrations, also in the $2239-2246 \mathrm{~cm}^{-1}$ region corresponding to $\mu_{\text {in }}$ band (functionality of AN monomer) and afterwards in the 3720$3280 \mathrm{~cm}^{-1}$ and $1717-1729 \mathrm{~cm}^{-1}$ range for characteristic vibrations of $v_{\text {oH }}$ and $v_{-c=0}$ groups, respectively (both associated with the carboxyl functionality of MAA monomer). The band between $2926-2939 \mathrm{~cm}^{-1}$ was assigned to $\mathrm{C}-\mathrm{H}$ groups of the polymer backbone (i.e. fig. 2.). In the spectra of MIP 1-10 before extraction (for instance fig. 2. a), the wide and strong band at around $3448 \mathrm{~cm}^{-1}$ indicates the existence of hydrogen intermolecular -OH groups (table 2), while the band at $1636 \mathrm{~cm}^{-1}$ corresponds to the aromatic $\mathrm{C}=\mathrm{C}$ groups ascribed to quinones (polyphenols). In all spectra of MIPs before extraction, the expected bands corresponding to $\mathrm{OH}$ groups (non-associated and intermolecularbonds) are not clearly observed because they overlap with the $-\mathrm{OH}$ groups of MAA. Interestingly, the stretching frequency of the $\mathrm{O}-\mathrm{H}$ group exhibited shifts from 3705 to 3620 and from 3440 to $3280 \mathrm{~cm}^{-1}$, which can be due to hydrogen bonds between hydroxyl groups contained in both $\mathrm{H} / \mathrm{PH}$ and MIPS. For MIPs before extraction, a new band around 1363-1364 $\mathrm{cm}^{-1}$ was distinguished. This observation was in agreement with the band from the FTIR spectrum of $\mathrm{H}$ and $\mathrm{PH}$. Other specific bands are overlapped: the band ascribed to $-\mathrm{C}=0$ of quinones in MIPs at around $1628-1636 \mathrm{~cm}^{-1}$ with the characteristic bands of aromatic $\mathrm{C}=\mathrm{C}$ groups between $1568-1570 \mathrm{~cm}^{-1}$ range and the bands between 1097-954 $\mathrm{cm}^{-1}$ assigned to carbonyl groups from naphtodianthrones with the ones attributed to MAA monomer. After washing with ethanol, no characteristic bands of $\mathrm{H} / \mathrm{PH}$ can be observed in the FTIR spectrum of MIPs after extraction, indicating that the phyto-template molecules were properly removed from the MIP pearls. Besides the H/PH-imprinting,

\begin{tabular}{|c|c|c|c|c|c|c|c|c|c|c|}
\hline $\begin{array}{c}\text { NTs } \\
\text { bands } \\
\left(\mathrm{cm}^{-1}\right)\end{array}$ & $\begin{array}{c}\text { voH } \\
\text { (non- } \\
\text { associate } \\
\text { d) }\end{array}$ & $\begin{array}{c}\text { vOH } \\
\text { (hydrogen } \\
\text { bonding) } \\
\text { (Ar-OH) }\end{array}$ & $\begin{array}{c}v C-H \\
\text { (alkyl) }\end{array}$ & $\begin{array}{c}D C=O \\
\text { (cetone) }\end{array}$ & $\begin{array}{c}v C=C \\
\text { (aromatic) } \\
v C=0 \\
\text { (quinone) }\end{array}$ & $v \mathrm{C}-\mathrm{CH} 3$ & \multicolumn{2}{|c|}{$\begin{array}{c}v_{\mathrm{C}-\mathrm{O}} \\
(\mathrm{Ar}-\mathrm{OH})\end{array}$} & \multicolumn{2}{|c|}{$\begin{array}{c}v_{C}-a, v_{C}=0 \\
(\mathrm{Ar}-\mathrm{COOH})\end{array}$} \\
\hline $\mathbf{H}$ & 3709 & 3448 & 2937 & 1738 & 1568 & 1453 & 1377 & 1229 & 1097 & 1026 \\
\hline PH & 3709 & 3447 & 2926 & 1744 & 1589 & 1458 & 1368 & 1238 & 953 & 835 \\
\hline
\end{tabular}

Table 2

MAIN CHARACTERISTIC BANDS OF H AND PH 

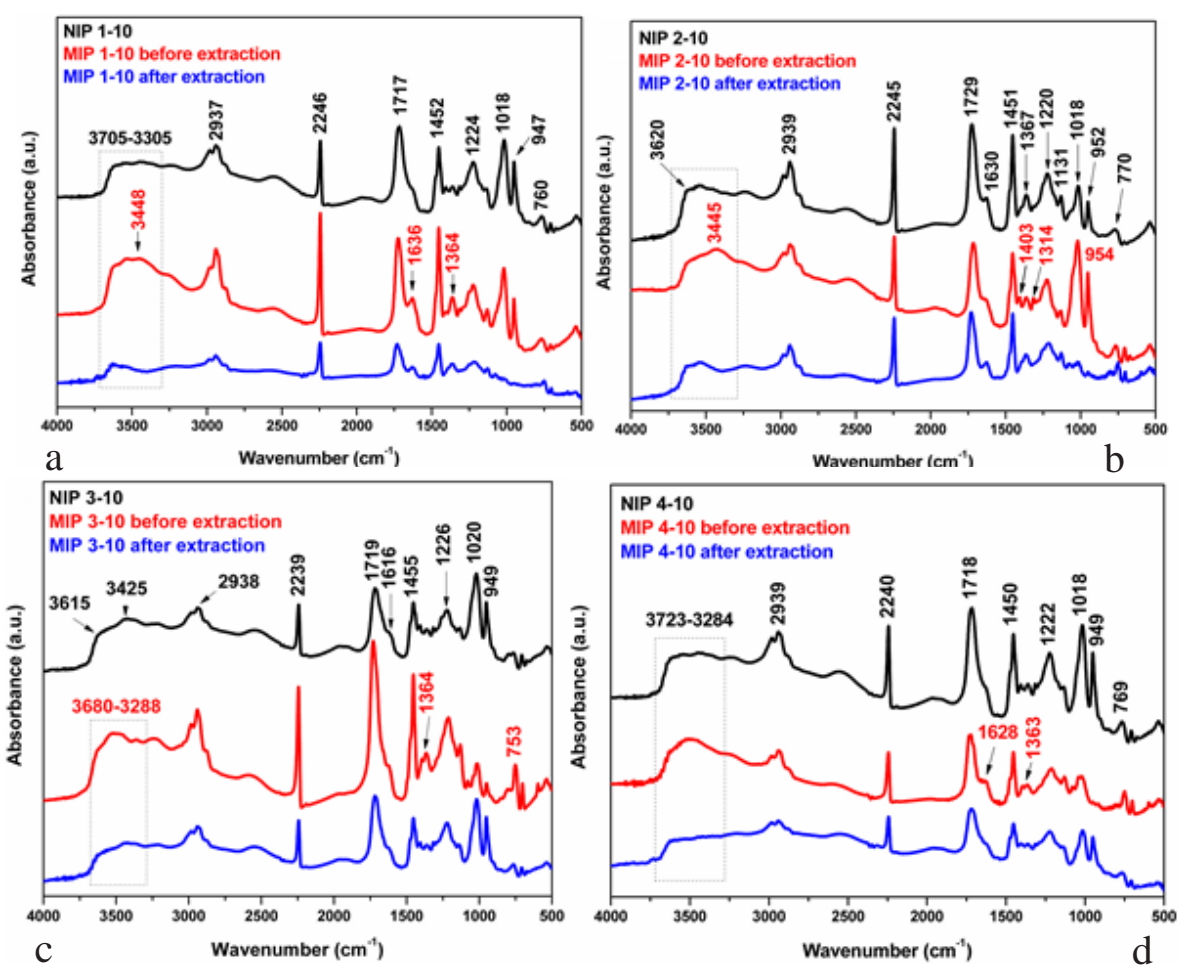

Fig. 2. FTIR spectra of a) MIP 1-10 b) MIP 2-10 c) MIP 3-10 and d) MIP 4-10 before and after phyto-template extraction compared to corresponding NIPs
FTIR results also validate the efficiency of the template removal procedure.

\section{Thermal properties}

The effect of the phyto-template onto the matrix structure was also confirmed by thermogravimetric analysis (table 3). It is relevant to note that the obtained pearls present quite good thermal resistance. As can be observed from the main decomposition parameters (table 3), the residue content decreases when MAA content increases. All the polymers present a first stage of weight

Table 3

THERMAL DECOMPOSITION DATA FOR NIPS AND MIPS PEARLS BEFORE AND AFTER EXTRACTION AND THEIR PHYSICAL PROPERTIES

\begin{tabular}{|c|c|c|c|c|c|c|c|c|}
\hline \multirow{2}{*}{$\begin{array}{c}\text { Polymer } \\
\text { NIPs/MIPs }\end{array}$} & \multicolumn{3}{|c|}{$\mathrm{T}_{\max }\left({ }^{\circ} \mathrm{C}\right)$} & \multirow{2}{*}{$\begin{array}{c}\text { Residue, } \\
800^{\circ} \mathrm{C}(\%)\end{array}$} & \multirow{2}{*}{$\begin{array}{l}\mathbf{m} w^{(b)} \\
(\mathrm{mg})\end{array}$} & \multirow{2}{*}{$\begin{array}{c}\mathrm{V}_{\mathrm{WW}} \sim \mathrm{V}_{\mathrm{p}}{ }^{\prime(c)} \\
(\mathrm{mL})\end{array}$} & \multirow{2}{*}{$\begin{array}{c}\mathrm{V}_{\mathrm{P}}^{\prime \prime} \\
(\mathrm{mL})\end{array}$} & \multirow{2}{*}{$\begin{array}{l}V^{(d)} \\
(\%)\end{array}$} \\
\hline & II & III & IV & & & & & \\
\hline MIP 1-5 before extraction & $\begin{array}{l}70.79 / \\
171.60\end{array}$ & & $68 / 407,27$ & 39.15 & 0.169 & 0.43 & 0.607 & 71.83 \\
\hline MIP $1-5$ after extraction & $\begin{array}{l}43,51 / \\
106,17\end{array}$ & & $46 / 412,39$ & 44.56 & - & - & - & - \\
\hline NIP 1-5 & 67.70 & & $\begin{array}{l}31 / 335,64 \\
420,53\end{array}$ & 48.56 & 0.19 & 0.41 & 0.607 & 68.33 \\
\hline MIP 2-5 before extraction & 70.79 & & $\begin{array}{l}17 / 294,96 / \\
401,08\end{array}$ & 39.7 & 0.144 & 0.46 & 0.618 & 76 \\
\hline MIP 2-5 after extraction & 119,43 & & $68 / 404,62$ & 41.1 & - & - & - & - \\
\hline NIP 2-5 & 150,82 & & $24 / 399,31$ & 34.32 & 0.173 & 0.43 & 0.618 & 71.16 \\
\hline MIP 3-5 before extraction & 151,29 & & $\begin{array}{l}80 / 346,56 / \\
411,83\end{array}$ & 37.95 & 0.098 & 0.50 & 0.620 & 83.66 \\
\hline MIP 3-5 after extraction & 109,20 & & $, 50 / 408,86$ & 39.36 & - & - & - & - \\
\hline NIP 3-5 & 153,41 & 242 , & $\begin{array}{l}6 / 334,89 / 40 \\
2,81\end{array}$ & 34.81 & 0.092 & 0.51 & 0.620 & 84.66 \\
\hline MIP 4-5 before extraction & 105,13 & & $\begin{array}{l}370,97 / \\
413,42\end{array}$ & 34.95 & 0.068 & 0.53 & 0.613 & 88.66 \\
\hline MIP 4-5 after extraction & 90.27 & & $, 17 / 391,14$ & 37.19 & - & - & - & - \\
\hline NIP 4-5 & 72.23 & & $44 / 398,57$ & 38.89 & 0.065 & 0.54 & 0.613 & 89.16 \\
\hline $\begin{array}{l}\text { MIP 1-10 before } \\
\text { extraction }\end{array}$ & 100,74 & $\begin{array}{r}30 \\
\text { shor }\end{array}$ & $\begin{array}{l}32 / 358,47 \\
\text { Ider } / 414,87\end{array}$ & 37.55 & 0.131 & 0.47 & 0.607 & 78.16 \\
\hline MIP 1-10 after extraction & 97.70 & & $02 / 407,60$ & 44.16 & - & - & - & - \\
\hline
\end{tabular}


Table 2 (continuated)

\begin{tabular}{|c|c|c|c|c|c|c|c|}
\hline NIP 1-10 & 120,97 & $312,56 / 401,68$ & 39,48 & 0.14 & 0.46 & 0.607 & 76.66 \\
\hline $\begin{array}{l}\text { MIP 2-10 before } \\
\text { extraction }\end{array}$ & 127,42 & $320,87 / 397,29$ & 39,77 & 0.138 & 0.46 & 0.618 & 77 \\
\hline MIP 2-10 after extraction & 130,45 & $312,99 / 397,29$ & 44,11 & - & - & - & - \\
\hline NIP 2-10 & 150,64 & $314,36 / 412,90$ & 36,87 & 0.129 & 0.47 & 0.618 & 78.5 \\
\hline $\begin{array}{l}\text { MIP 3-10 before } \\
\text { extraction }\end{array}$ & 134,47 & $\begin{array}{c}322,95 \text { shoulder } \\
/ 406,33\end{array}$ & 34,92 & 0.089 & 0.51 & 0.620 & 85.16 \\
\hline MIP 3-10 after extraction & 137,50 & $330,53 / 385,11$ & 34,60 & - & - & - & - \\
\hline NIP 3-10 & 156,20 & 399,76 & 32,67 & 0.078 & 0.52 & 0.620 & 87 \\
\hline $\begin{array}{c}\text { MIP 4-10 before } \\
\text { extraction }\end{array}$ & 166,23 & $342,10 / 385,95$ & 36,91 & 0.058 & 0.54 & 0.613 & 90.33 \\
\hline MIP 4-10 after extraction & 137,03 & $\begin{array}{c}320,33 \text { shoulder } \\
/ 407,54\end{array}$ & 33,69 & - & - & - & - \\
\hline NIP 4-10 & 141,04 & $325,48 / 395,21$ & 37,11 & 0.06 & 0.54 & 0.613 & 90 \\
\hline
\end{tabular}

(a) $m$, the weight of dried pearls (600 $\mathrm{mg}$ of wet sample).

(b) $V_{w}$, the water volume determined thermo-gravimetrically considering $600 \mathrm{mg}$ of wet pearls (values of water volume were equivalent to the pore volume, $V p^{\prime}$ )

(c) $V$, the mean pore volume calculated relative to the hydrodynamic volume of wet pearls, Vp" (600mg of wet sample);

loss between $40-150^{\circ} \mathrm{C}$, which is assigned to the adsorbed water, ethanol or solvent evaporation. The weight loss between $150-200^{\circ} \mathrm{C}$ is probably attributed to the thermal degradation of naphtodianthrones (demethylation), known for being temperature-sensitive. Afterwards, one may notice a degradation step (cyclization peak) between 315$325^{\circ} \mathrm{C}$ for NIPs and at around $310-360^{\circ} \mathrm{C}$ for MIPs; the shift of peak can be due to intramolecular bonding with the phyto-template. The weight loss is higher for the imprinted polymers with $10 \%$ of extract compared to those with $5 \%$, due to the difference between the extract contents. Further on, the evaluation of pearls internal pore volume, $V(\%)$, was realized by hydrodynamic measurements (table 3 ). The results indicated that the obtained pearls exhibited mean pore volumes up to $90 \%$ relative to total pearl volume, $V_{p}^{\prime \prime}(\mathrm{mL})$. Moreover, the increase of MAA concentration into copolymer led to pearls with higher pore volume; these remarks are sustained by the fact that carboxyl functional groups generate polymers with higher hydrophilicity than acrylonitrile.

\section{Batch binding and selectivity experiments}

The selective binding character was investigated using a purified and concentrated naphtodianthrone phyto-extract of $0.03 \mathrm{wt} . \%$ NTs (the same one used for imprinting) in batch mode. The imprinting effect was quantified and the selectivity of pearls for $\mathrm{H}$ or $\mathrm{PH}$ was evaluated against each other. Herein, almostall of the imprinted polymers exhibited higher adsorption capacities than the corresponding nonimprinted blanks (table 4) leading to relatively high values of imprinting factors (IF) from 1 to 2.89 for $\mathrm{H}$ and from 0.4 to 1.6 for $\mathrm{PH}$, respectively (fig. 3). Obviously, the imprinting factors for $\mathrm{H}$ and $\mathrm{PH}$ showed differentadsorption maximum because the MAA content into matrix is variable. Higher binding capacities $\left(Q_{H}, Q_{p H}\right)$ were observed for MIP $x-5$ pearls (table 4). Meanwhile, it could be seen that the adsorption capacities increased with the MAA content and decreased with the phyto-extract content. It is important to noted that the MIP $x-10$ and MIP $x-10$ systems re-bind both the $\mathrm{H}$ and the $\mathrm{PH}$ in an equilibrated way working as a simultaneous solid phase extractor. On the other hand, MIP 4-5 (fig. 3) registered a preferential adsorption for $\mathrm{H}$ $(\mathrm{IF}=2.89)$. Our previous work had proved that this behavior is based on the difference of water solubility between $\mathrm{H}$ (water non-soluble) and PH ( $33 \mathrm{mg} / \mathrm{L}$ solubility in water) found together in the NT extract [20]. Therefore, PH imprinting was less pronounced at low extract concentrations. The selectivity coefficients, $k$, ranged from 0.23 to 4.01 for $\mathrm{H}$ and from 0.25 to 4.35 for PH (table 4) which prove the selective character of MIPs. Distribution coefficients, $K_{n,}$ and relative selectivity coefficients, $k^{\prime}$, were also calculated and presented in table 4 . The enhanced values of $k^{\prime}$ for $\mathrm{H}$ (around 10 for MIP 2-5) are in agreement with $\mathrm{k}$ and IF values, indicating that the obtained imprinted systems presented higher binding affinities for $\mathrm{H}$ compared to $\mathrm{PH}$.

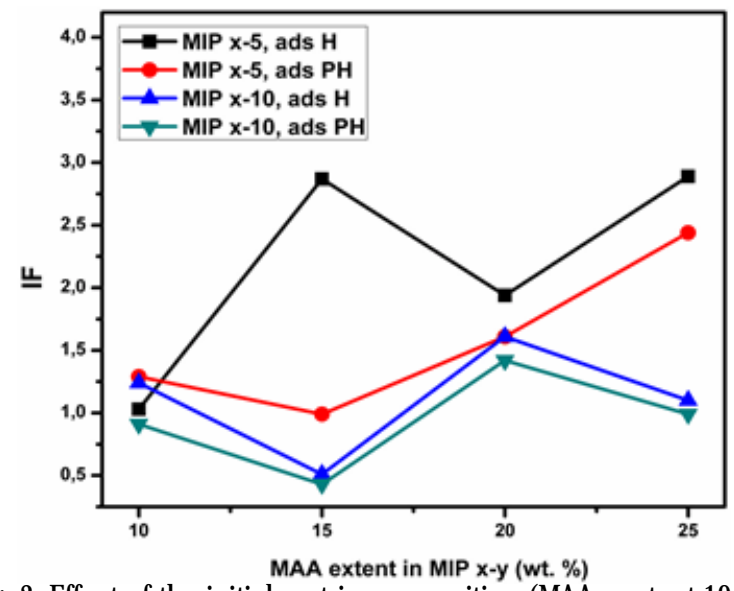

Fig. 3. Effect of the initial matrix composition (MAA content 10; 15; 20 and $25 \%$ ) on the imprinting factor, IF, of the polymers 
Table 4

THE VALUES OF MIPS/NIPS ADSORPTION CAPACITIES, Q, FOR H AND PH, DISTRIBUTION COEFFICIENTS, Kd, SELECTIVITY COEFFICIENTS, k, AND RELATIVE SELECTIVITY COEFFICIENTS, k', RESPECTIVELY, OF MIP X-Y AND NIP X-Y PEARLS

\begin{tabular}{|c|c|c|c|c|c|c|c|c|}
\hline $\begin{array}{c}\text { MIP x-y/ } \\
\text { NIP x-y }\end{array}$ & $\begin{array}{c}\mathbf{Q P H} \\
(\mathbf{m g} / \mathbf{g})\end{array}$ & $\begin{array}{c}\mathbf{Q H} \\
(\mathbf{m g} / \mathbf{g})\end{array}$ & $\begin{array}{c}\mathbf{K d P H}-\mathrm{H} \\
\mathbf{( m L / g})\end{array}$ & $\begin{array}{c}\mathbf{K d H}-\mathrm{PH} \\
(\mathbf{m L} / \mathbf{g})\end{array}$ & $\mathbf{k P H}$ & $\mathbf{k H}$ & $\mathbf{k P H}^{{ }^{(\mathbf{a})}}$ & $\mathbf{k H}^{\mathbf{}^{(\mathbf{b})}}$ \\
\hline MIP 1-5 & 2.45 & 1.18 & 22.73 & 12.19 & 1.86 & 0.54 & 1.44 & 0.69 \\
\hline NIP 1-5 & 1.98 & 1.14 & 16.41 & 12.70 & 1.29 & 0.77 & - & - \\
\hline MIP 1-10 & 2.15 & 0.71 & 14.12 & 5.39 & 2.62 & 0.38 & 0.60 & 1.66 \\
\hline NIP 1-10 & 2.37 & 0.55 & 17.49 & 4.019 & 4.35 & 0.23 & - & - \\
\hline MIP 2-5 & 0.81 & 1.45 & 3.89 & 15.58 & 0.25 & 4.01 & 0.09 & $\mathbf{1 0 . 8 4}$ \\
\hline NIP 2-5 & 1.58 & 0.51 & 10.25 & 3.78 & 2.71 & 0.37 & - & - \\
\hline MIP 2-10 & 1.68 & 1.58 & 10.01 & 17.63 & 0.57 & 1.76 & 0.19 & 5.38 \\
\hline NIP 2-10 & 3.95 & 1.60 & 52.11 & 17.06 & 3.05 & 0.33 & - & - \\
\hline MIP 3-5 & $\mathbf{3 . 1 4}$ & $\mathbf{1 . 6 9}$ & 21.94 & 15.73 & 1.39 & 0.72 & 0.85 & 1.18 \\
\hline NIP 3-5 & 1.95 & 0.87 & 10.50 & 6.41 & 1.64 & 0.61 & - & - \\
\hline MIP 3-10 & $\mathbf{3 . 5 6}$ & $\mathbf{1 . 8 4}$ & 25.41 & 16.97 & 1.49 & 0.67 & 0.92 & 0.08 \\
\hline NIP 3-10 & 2.51 & 1.14 & 13.94 & 8.58 & 1.63 & 0.62 & - & - \\
\hline MIP 4-5 & $\mathbf{3 . 3 9}$ & $\mathbf{2 . 8 8}$ & 20.11 & 29.61 & 0.68 & 1.48 & 0.27 & 3.74 \\
\hline NIP 4-5 & 3.17 & 1.00 & 17.94 & 7.07 & 2.54 & 0.39 & - & - \\
\hline MIP 4-10 & $\mathbf{2 . 7 8}$ & $\mathbf{3 . 6 2}$ & 14.45 & 39.11 & 0.37 & 2.71 & 0.23 & 3.57 \\
\hline NIP 4-10 & 2.79 & 1.48 & 14.75 & 11.19 & 1.32 & 0.76 & - & - \\
\hline
\end{tabular}

(a) Selectivity coefficient of $P H$ against $H$ attained for MIP $x$-y pearls relative to NIP $x-y$

(b) Selectivity coefficient of $H$ against $P H$ attained for MIP $x-y$ pearls relative to NIP $x-y$

\section{Conclusions}

The MIP pearls described in this paper exhibited similar and reproducible physico-chemical characteristics with our previous reported studies [20]. The adsorption capacities of MIPs and the imprinting factors were more pronounced at higher MAA contents, which was in agreement with former results. Yet, higher selectivity coefficients $(k \sim 4)$ were recorded for the MIP 2-5 system, instead of $k \sim 2$ compared to our previous work. These results prove the MIP systems obtained with a more concentrated NTs extract as template were successfully improved; and therefore, the main goal of our study was achieved.

Acknowledgments: The work has been funded by the Romanian National Research Programs -Project 34 N/15.03.2016, No. PN.16.31.02.02.02 and by the Project Partnership no. 44/2015 BIOGELFARM.

\section{References}

1. POLYAKOV, M.V., Zhur. Fiz. Khim., 2, 1931, p. 799.

2. WULFF, G., SARHAN, A., Angew. Chem. Int. Ed. Engl., 11, 1972, p.
3. BELTRAN, A., BORRULL F., CORMACK, P.A.G., MARCÉ, R.M., Trends In Anal. Chem., 29, no. 11, 2010, p. 1363.

4. SARBU, A., IORDACHE, T.V., FLOREA, A.-M., Molecularly Imprinted Polymers (MIPs) Challenges, Uses and Prospects, 3, Nova Publishers, QUINN, T., New York, 2017, p. 119.

5 WHITCOMBE, M.J ., KIRSCH, N., NICHOLLS, I.A., J. Mol. Recognit, 27, no. 6, 2014, p. 297.

6. NICOLESCU, T-V., SÂRBU, A., GHIUREA, M., DONESCU, D., U.P.B. Sci. Bull., Series B, 73, no.1, 2011, p. 163.

7. DIMA, S.O., MEOUCHE, W., DOBRE, T., NICOLESCU, T-V., SÂRBU, A., Reac. Funct. Polym., 73, 2013, p. 1188.

8. FLOREA, A. M., SARBU, A., IORDACHE, T.V., GAREA, S.-A., SANDU, T., APOSTOL, S., HUBCA, GH., U.P.B. Sci. Bull., Series B, 77, no. 4, 2015, p. 3.

9. LAZAU, C., IORDACHE, T.-V., FLOREA, A.-M., ORHA, C., BANDAS, C., RADU, A.-L., SARBU, A., T. ROTARIU, Appl. Surface Sci., 384, 2016, p. 449.

10. ERTURK, G., MATTIASSON, B., Sensors, 17, no. 2, 2017, p. 288.

11. VOICU, A.-E., ROTARIU, T. , TEODORESCU, M., ZECHERU, T., TIGANESCU, T.-V., ORBAN, O., Mat. Plast., 54, no. 1, 2017, p. 103. 
12. NICOLESCU, T.-V., MEOUCHE, W., BRANGER, C., MARGAILLAN, A., SARBU, A., DONESCU, D., J Polym Res, 19, no. 2, 2012.

13. KLAPOETKE, ROTARIU, T.,TH., STIASNY, B., STIERSTORFER, J., WIEGMANN, S., ZECHERU, T., Eur. J. Org. Chem., 25, 2016, pp. 4382. 14. Petre, R., ZeCherU, T., PETREA, N., ROtARIU, T., Rev. Chim.(Bucharest), 67, no.12, 2016, p. 2464

15. ANSARI, S., KARIMI, M., Trends in Anal. Chem., 89, 2017, p. 146.

16.MOLERIU, L., JIANU, C., BUJ ANCA, G., DOROS, G., MISCA, C., ILIE, O.-C., MOLERIU, R.-D., ILIE, A.-C., Rev. Chim.(Bucharest), 68, no. 4, 2017, p. 687
17. MARRELLI, M., STATTI, G., CONFORTI, F.1, MENICHINI, F., Mini. Rev. Med. Chem., 16, no. 9, 2016, p. 710.

18. ASGARPANAH, J., Afr. J. Pharm. Pharmacol., 6, 2012, p. 1387.

19. LI, Z., QIN, C., LI, D., HOU, Y., LI, S., SUN, J., J. Pharm. Biomed. Anal. 98, 2014, p. 210.

20. FLOREA, A. M., IORDACHE, T-V., BRANGER, C., GHIUREA, M., AVRAMESCU, S., HUBCA, G., SARBU, A., Talanta, 148, 2016, p. 37.

Manuscript received: 30.02 .2017 